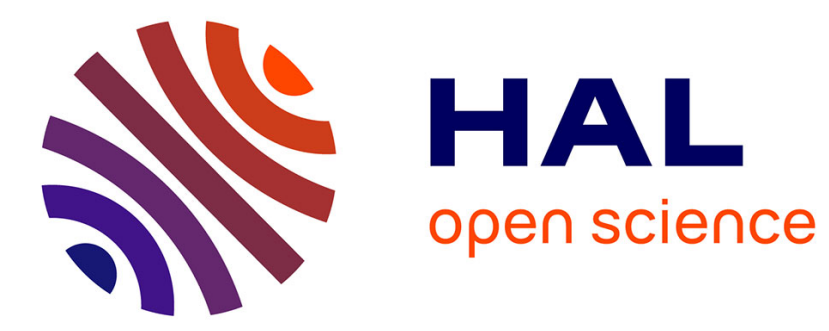

\title{
NUMERICAL MODELLING OF COMPOSITE BEAM-TO-BEAM JOINTS-INNOVATIVE SOLUTIONS
}

\author{
Samy Guezouli, Hugues Somja, Sao Serey Kaing, Alain Lachal
}

\section{- To cite this version:}

Samy Guezouli, Hugues Somja, Sao Serey Kaing, Alain Lachal. NUMERICAL MODELLING OF COMPOSITE BEAM-TO-BEAM JOINTS-INNOVATIVE SOLUTIONS. 6th International Conference on Composite Construction in Steel and Concrete, Jul 2008, Tabernash, CO, United States. pp.542-553, 10.1061/41142(396)44 . hal-00967002

\section{HAL Id: hal-00967002 https://hal.science/hal-00967002}

Submitted on 28 Mar 2014

HAL is a multi-disciplinary open access archive for the deposit and dissemination of scientific research documents, whether they are published or not. The documents may come from teaching and research institutions in France or abroad, or from public or private research centers.
L'archive ouverte pluridisciplinaire HAL, est destinée au dépôt et à la diffusion de documents scientifiques de niveau recherche, publiés ou non, émanant des établissements d'enseignement et de recherche français ou étrangers, des laboratoires publics ou privés. 


\title{
NUMERICAL MODELLING OF COMPOSITE BEAM-TO-BEAM JOINTS - INNOVATIVE SOLUTIONS
}

\author{
Samy GUEZOULI \\ Samy.Guezouli@insa-rennes.fr \\ Hugues SOMJA \\ Hugues.Somja@insa-rennes.fr \\ Sao Serey KAING \\ ksserey@yahoo.fr \\ Alain LACHAL \\ Alain.Lachal@insa-rennes.fr \\ LGCGM - Structural Engineering Research Group, \\ INSA Rennes, France
}

\begin{abstract}
This paper deals with a numerical F.E. modelling investigation of new joint typology to connect continuously composite beams in bridges. Different types of joint have been selected, designed and tested under fatigue and monotonic loading. For an accurate interpretation of the test results and a better understanding of some specific behaviours (not accessible to measurement) with complex geometries and with the objective to generalize the study, numerical models have been developed using several Finite Element programs including specific programs for composite beams and 3D models based on standard FEM codes. The main numerical results are presented and compared against experimental ones.
\end{abstract}

\section{INTRODUCTION}

In order to promote new composite techniques for bridges of small and medium spans, innovative solutions have been investigated for the design and the fabrication of beam-to-beam joints. In Europe, several projects have been carried out on this subject the past few years [ECCS, 2000]. In France, taking benefit of a National Research Project, the Laboratory of Structural Mechanics at INSA in Rennes has undertaken research work to find new types of beam-to-beam joint ensuring the continuity of composite beam in bridges. New joint solutions have been selected [Lachal A. et al., 2002] with the aim to find economic solutions using, if possible, standardized or ordinary prefabricated elements easily mounted on site by a same builder with a minimum of construction operations and without any sophisticated technology (as outdoor welding for example). Analytical methods have been developed for these new joints and used to design and fabricate test specimens, approximately at half scale of the actual bridges. Specimens have been tested on the platform of the Laboratory under fatigue and monotonically increasing loading up to the specimen collapse.

For an accurate interpretation of monotonic test results and a better understanding of some specific behaviours numerical models have been created. In addition, these models are also able to give information not accessible to measurement. Several Finite Element programs were used depending on the nature of the investigated phenomena. These include specific beam FE 
models developed or co-developed (de Ville V., 1988) by the group and 3D models based on CASTEM code. This paper gives a description of these finite element models used for this research. The numerical models have been calibrated against experimental results and scientifically adjusted to take into account the contribution of several components in the global behaviour of the joints.

The main result deals with the ability of the numerical models to simulate the flexural behaviour of the joints. Very useful local information are also obtained with the prospects to develop design methods for these joints.

\section{PRESENTATION OF THE SELECTED BEAM-TO-BEAM JOINTS TO BE STUDIED}

The joints of the beam-to-beam specimens tested at INSA in Rennes are illustrated in the Figures 1, 2 and 3.

For all the joints, steel girders are HEA 500 rolled sections in steel grade S355. The width of the slab is $1600 \mathrm{~mm}$ and the thickness is $160 \mathrm{~mm}$. The strength class C45/55 is used for the concrete. The transfer of the tensile forces in the upper part of the joint is allowed by the shear connection and the reinforcement in the slab. In the reinforced zone around the beam-to-beam connection, the longitudinal reinforcement consists of 2 layers of ribbed bars ( $4100 \mathrm{~mm}$ length) of $17 \Phi 16$ with high bond action and with steel grade S500 - Category 3, ensuring high ductility (the percentage of longitudinal reinforcement being $2.67 \%$ ). The slab is connected to the steel flange with 12 welded headed studs per meter $(\Phi 22 \mathrm{~mm}$ and $\mathrm{h}=125 \mathrm{~mm})$. Outside the connection zone, the percentage of reinforcement is $1.26 \%$ (composed of 2 layers of ribbed bars of $8 \Phi 16$ ) and the number of connectors is 6 studs/meter. Steel girders were prepared in factory (ArcelorMittal - Wallerich - Differdange) and equipped with additional plates and welded studs. They were transported to INSA in RENNES where the reinforcement was installed and the continuity of the composite beam was completed by concreting the slab and the joint in a single shot.

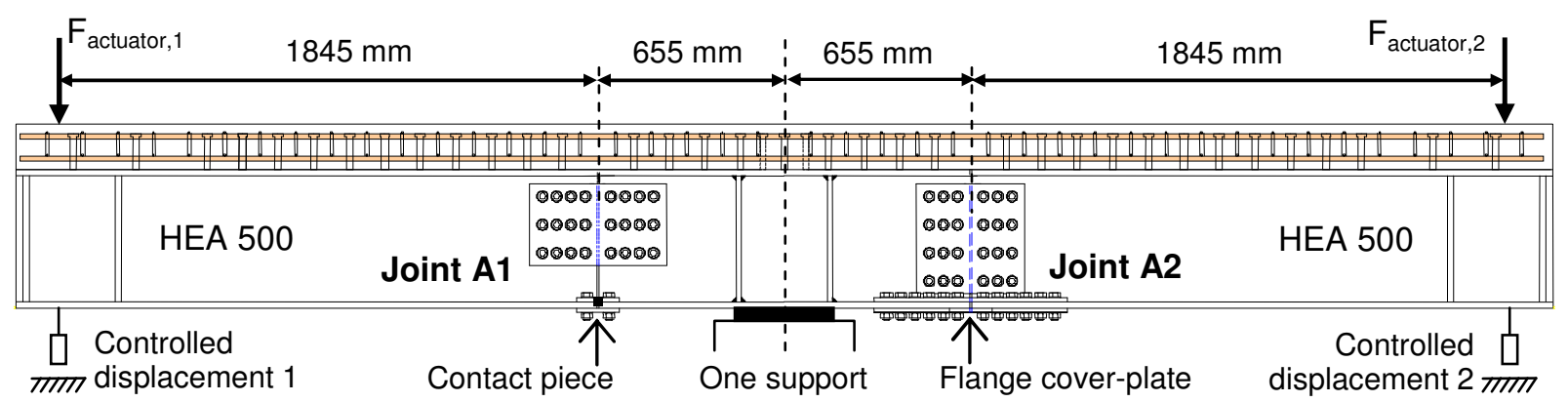

Fig. 1 - Joint with bolted cover-plates (and direct contact)

The first type of joint is presented in Figure 1. Steel girders are connected with cover-plates and high strength bolts. On the upper side, the tensile forces are directly transferred from top flanges to the reinforcement of the slab through the shear connection. A new technology has been developed with a direct contact between compressed bottom flanges (Figure 1) in order to avoid flange cover-plates and so to reduce considerably the number of bolts. Such a type of joint may be located anywhere along the span. In fact, it will be more often located near an intermediate support where the bending moment is low. This type of joint remains easy to build on site and presents the advantage of having no welds subjected to fatigue. 


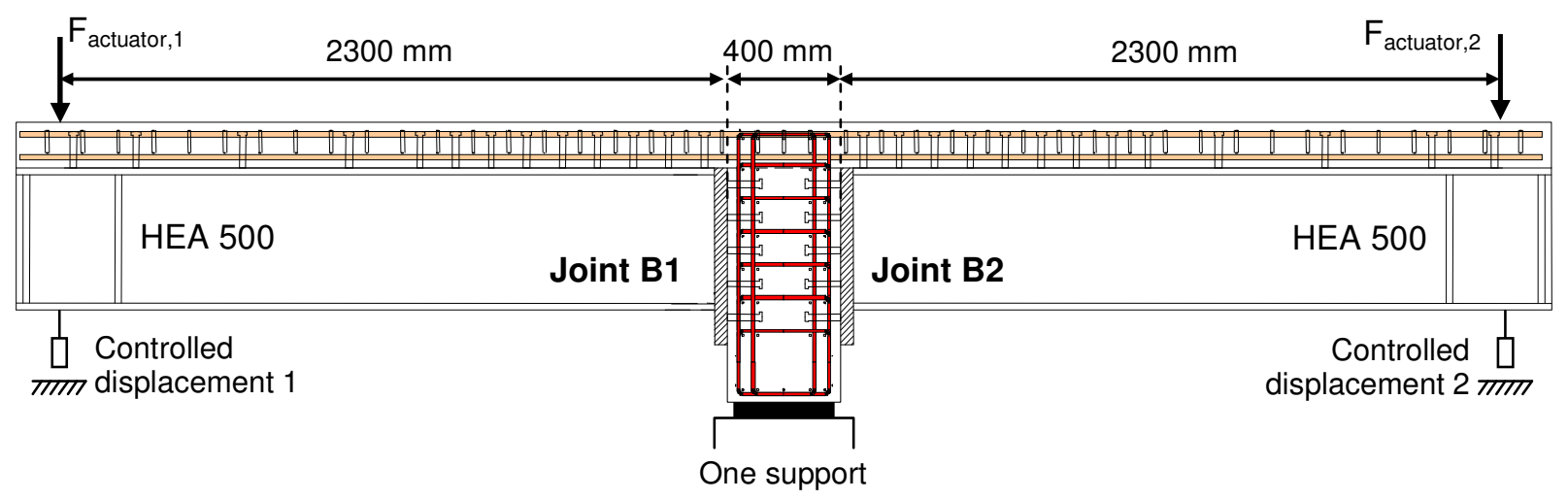

Fig. 2 - Beam-to-beam joint with butt-plates and shear studs connected to a transversal concrete beam.

The second type of joint is presented in Figure 2. Steel girders are equipped with butt-plates welded at their ends. These are connected with shear studs to a transverse deep beam lying on an intermediate pier. This type of joint is necessarily located at intermediate support.

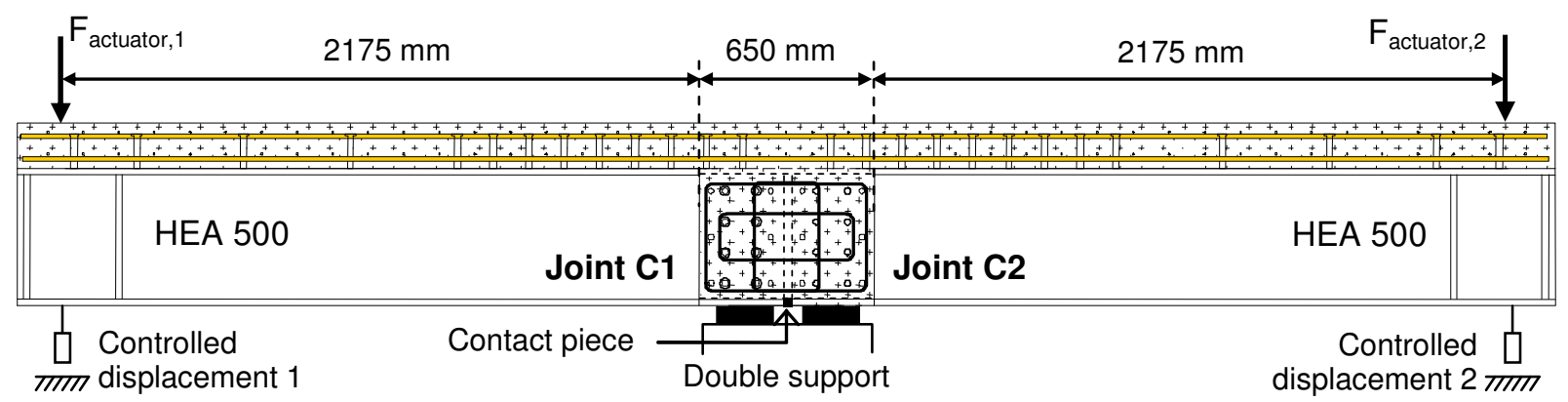

Fig. 3 - Beam-to-beam joint with concrete embedding.

The third type of joint is presented in Figure 3. Both ends of steel girders are embedded in a concrete block resisting over the pier. Each steel girder lies directly over its own support in order to avoid a shear force transfer through the mid-cross-section of the embedding. A direct contact between the ends of the bottom flanges of the girders over the support ensures the transfer of the compression forces in the joint. Shear studs welded on the webs and/or rebars passing through the webs are used to connect the steel girders inside the block embedding.

Most part of analytical mechanical models used to design the joint specimens presented under above are novel in so far as Eurocodes (EN 1994-2) does not give specific provisions to design beam-to-beam joints in continuous composite bridges. So, some of these joints overall and local behaviour need to be checked against experimental test results and numerical ones in order to be better understood.

Loading and support arrangements used for the tests are indicated in Figures 1, 2 and 3. Main measurements devices during the tests are : inclinometers, linear potentiometric transducers and strain gauges used to measure the joint rotation, deflections, relative displacements (slips) and strains at several parts of the specimen. Crack widths were measured on the top surface of the concrete slab. More information about details and results of this experimental study can be found in a companion paper [Lachal A. et al., 2008]. 


\section{PRESENTATION OF THE FINITE ELEMENT MODELS DEVELOPPED FOR THIS STUDY AND SOME NUMERICAL RESULTS}

\section{Short overview of available finite element techniques}

For global analysis of continuous composite bridges, a specific fiber beam element accounting for partial shear interaction was developed (see for instance [XU H. et al., 2000]). These beam elements are able to accurately model the nonlinear shear force-slip behaviour and to give accurate internal force distribution for standard continuous composite beams. For a more detailed analysis, 3D F.E. modeling cannot be avoided. 3D F.E. models of composite beams proposed in the literature often involves shell elements to model both the deck and the girders and beams for the connection [Ahmed B. et al., 1995]. Recently, several authors have been using 3D elements for all the components of the composite beam and joint [Fu F. et al. 2007, Sieffert Y. et al 2006, Chung W. 2006].

In the numerical study presented in this paper, the whole state-of-the-art finite element software has been taken into account and different numerical solutions have been selected according to the specific research objectives for each joint.

\section{Shell and 3D beam finite element model applied to joints $A 2$ with cover-plates}

A simplified 3D finite element model is proposed for the joint with cover-plates (test specimen of type A). For reminder, the joint is located at a distance of $655 \mathrm{~mm}$ from the mid-support axis. In spite of the asymmetry of the specimen with respect to the mid-axis, the present numerical simulation considers only the right side part from the mid-axis (joint A2) with the possibility to replace the flange cover-plates by a simple contact for future numerical simulations. The most important aspects for this joint is the influence of the discontinuity of the girder (especially the one at the top flange) on the joint behaviour (moment-rotation curve) and the slip of the studs along the beam. All material behaviours are elasto-plastic with kinematic hardening (E/10). The Young's modulus E, the yield and the ultimate stresses are given in table 1.

Table 1 - Material mechanical characteristics (MPa).

\begin{tabular}{|c|c|c|c|c|c|}
\hline Material & Steel girder & Stiffeners & Cover-plates & Bars & Studs \\
\hline Young's modulus & 200000 & 200000 & 200000 & 200000 & 200000 \\
\hline Yield stress & 430 & 430 & 385 & 600 & 350 \\
\hline Ultimate stress & 525 & 525 & 580 & 680 & 660 \\
\hline
\end{tabular}

The F.E. discretization and the main hypotheses are summarized below :

- The concrete slab is supposed completely cracked and its strength in tension is neglected.

- The reinforced bars are replaced by an equivalent "plate". Its width is equal to the flange one, its thickness and its position with respect to the top flange are calculated by imposing a geoemetric and material equivalence with the actual cross-section with rebars. This equivalence concerns the second moment of area and the position of the centroid of the cross-sections. This equivalent "plate" is modeled with shell finite elements.

- The girder, the stiffeners and the cover-plates are meshed with shell finite elements. 
- The studs are meshed with 3D beam finite elements (to ensure the displacement compatibility with shell elements). The stud has a common node with the equivalent "plate". The slip of the stud is defined in figure 4.

- The cover-plates are connected to the girder with high strength preloaded bolts. The connection of the cover-plates has been designed in order to be slip-resistant using 10.9 bolts and a class $B$ or $A(\mu \geq 0.4)$ of surface friction. In this case, the cover-plates remain in contact with the girder during the test and the solutions with or without bolts (direct contact between the cover-plates and the girder) appear to be equivalent.

The numerical simulation predicts a higher rotation capacity of the joint than the one calculated from the experimental results (Figure 5). Its seems that, even if the specimen is tested under negative bending moment, the concrete being in different stages of cracking could give an additional stiffness thanks to the tension stiffening effect. Since the concrete in tension is completely neglected, beneficial effect from tension stiffening is not taken into account. Accordingly, we can expect an overestimation of the rotation capacity by the numerical model. On the right side of the discontinuity, the experimental and numerical results of the studs slip (Figure 6) are close together while on the left side, the results appear different. On this side, the transfer of the internal forces from the top of the flange to the reinforcing bars through the studs hides some local phenomena that the present $3 \mathrm{D}$ model is not able to reveal.

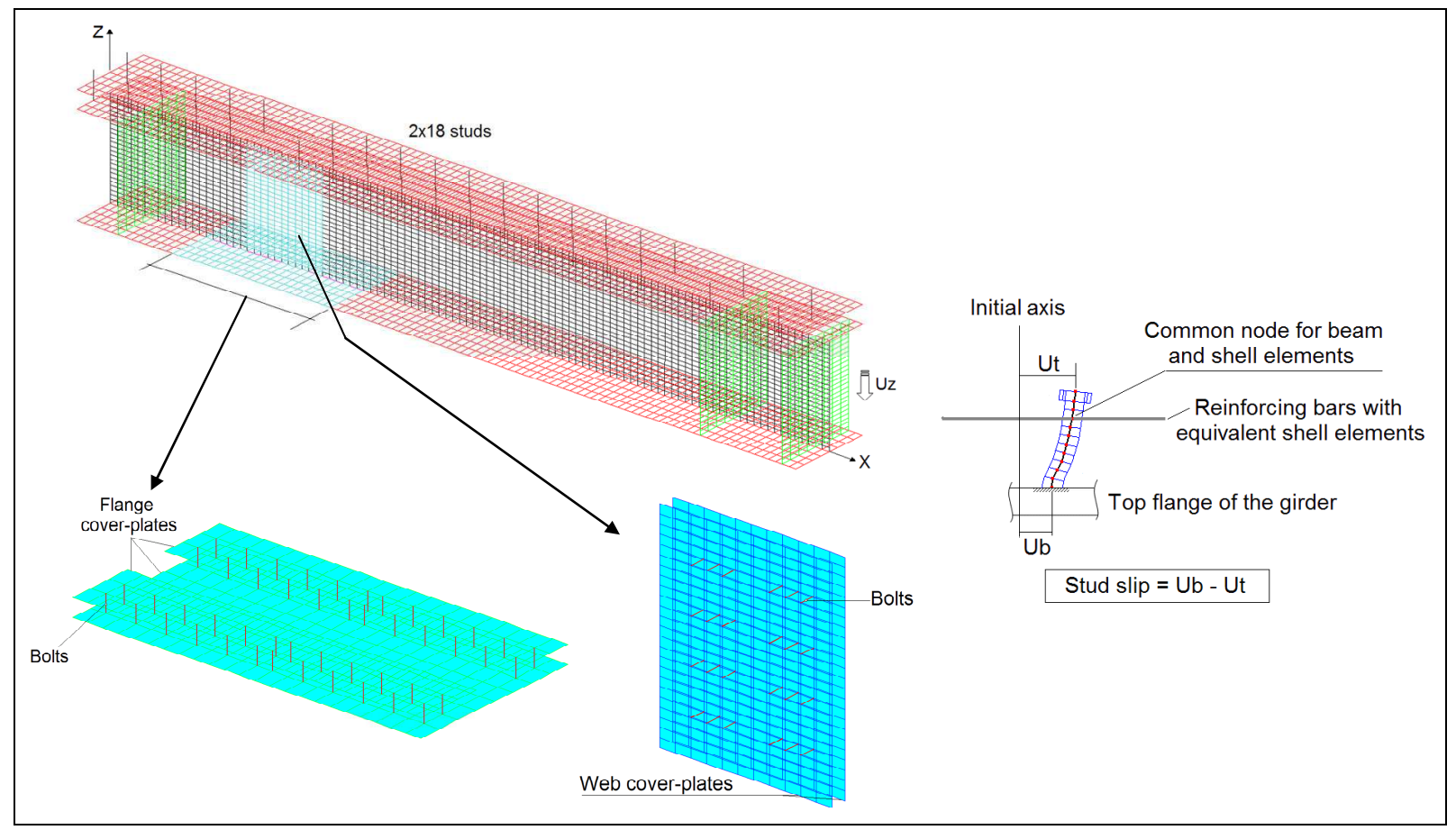

Fig. 4 - Simplified 3D model details. 


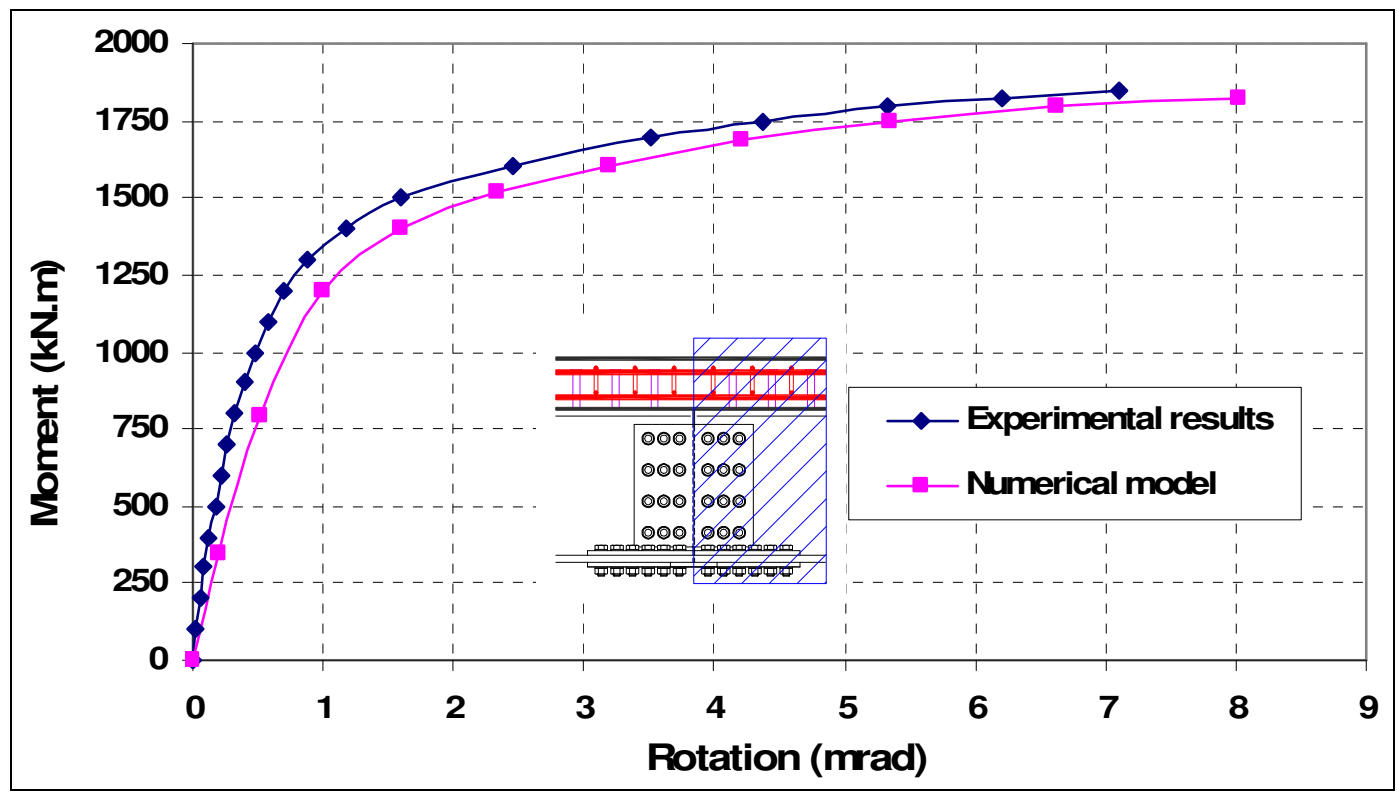

Fig. 5 - Moment-Rotation curve of the joint.

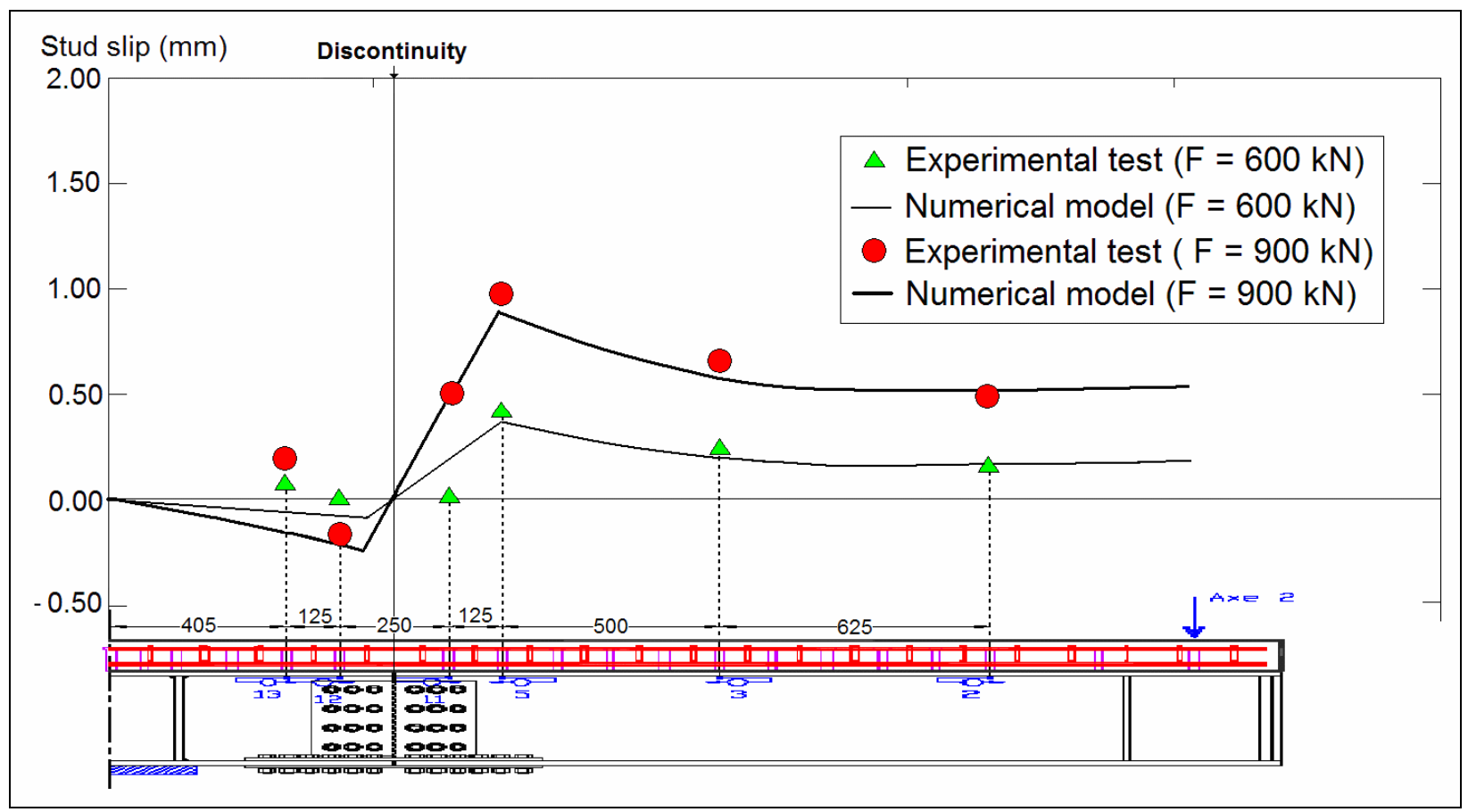

Fig. 6 - Slip of the studs along the specimen.

\section{D solid finite element model applied to joint $B$ with butt-plates}

For the specimen $\mathrm{B}$, the $3 \mathrm{D}$ finite element model is more detailed than the previous one. The whole specimen is modeled with cubic solid elements ( 3 d.o.f. per node) taking into account the concrete as-well-as the real number and position of longitudinal and transverse reinforcing bars in the slab. The single simplification concerns the deep beam resting on the support where the reinforcement is too complex to be modeled with solid elements. Therefore, the reinforced 
concrete of the deep beam has been replaced by an equivalent homogeneous material. Details are given in Figures 7, 8 and 9. The adherence between (the girder and the slab) and (the concrete joint and the butt-plate) could be either neglected (in this case the interfaces are empty and the connexion is only carried out by the vertical and horizontal studs), or modeled with a material having a very low Young's modulus. According to the experimental specimen, the percentage of longitudinal reinforcement is reduced at $2050 \mathrm{~mm}$ from the middle axis of the joint. During the cyclic preloading, the slab concrete of the specimen was cracked. To take into account this initial cracking in the numerical model, a reduced elastic concrete modulus of $\mathrm{E}_{\mathrm{a}} / 100=2000 \mathrm{MPa}$ has been adopted over a length of $600 \mathrm{~mm}$ from the butt-plate.

Except concrete, all material behaviours are elasto-plastic with kinematic hardening (E/10). For concrete, the model proposed by Mazars (elasto-plastic behaviour including damage) is well adapted for monotonic loading. The comparison between experimental and numerical results is shown in figures 10 and 11. This comparison concerns different load levels (200 kN - $600 \mathrm{kN}-$ $900 \mathrm{kN}$ for experimental test) and (220 kN - 610 kN - $920 \mathrm{kN}$ for numerical calculation). These last values are not exactly the same because the numerical model is loaded with imposed displacement and the corresponding load is calculated at the mid-support. The longitudinal displacements of the butt-plate are plotted in figure 10. The comparison seems to be more accurate for low load levels than for high ones, especially at the top of the butt-plate. The curves of the studs slip along the specimen are plotted in figure 11. The decreasing of these curves around $800 \mathrm{~mm}$ on X-axis seems to be due to the cracking slab just near the joint as modeled in figure 8. The results could be more accurate if the slab cracking is taken into account continuously from the butt-plate to the end of the specimen but this correction is difficult to be estimated.

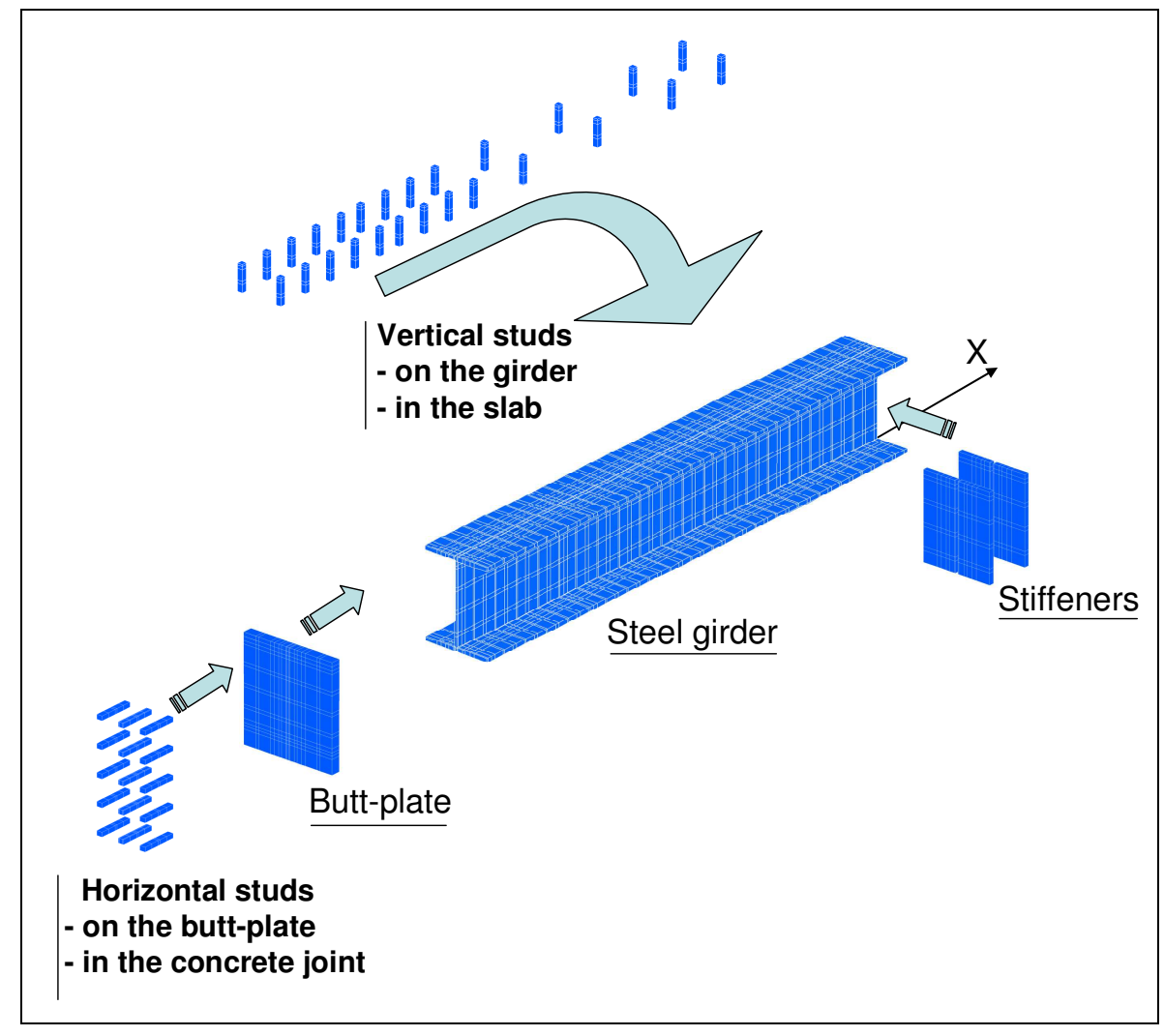

Fig. 7 - 3D model details - Steel girder - Studs - Butt-plate - Stiffeners. 


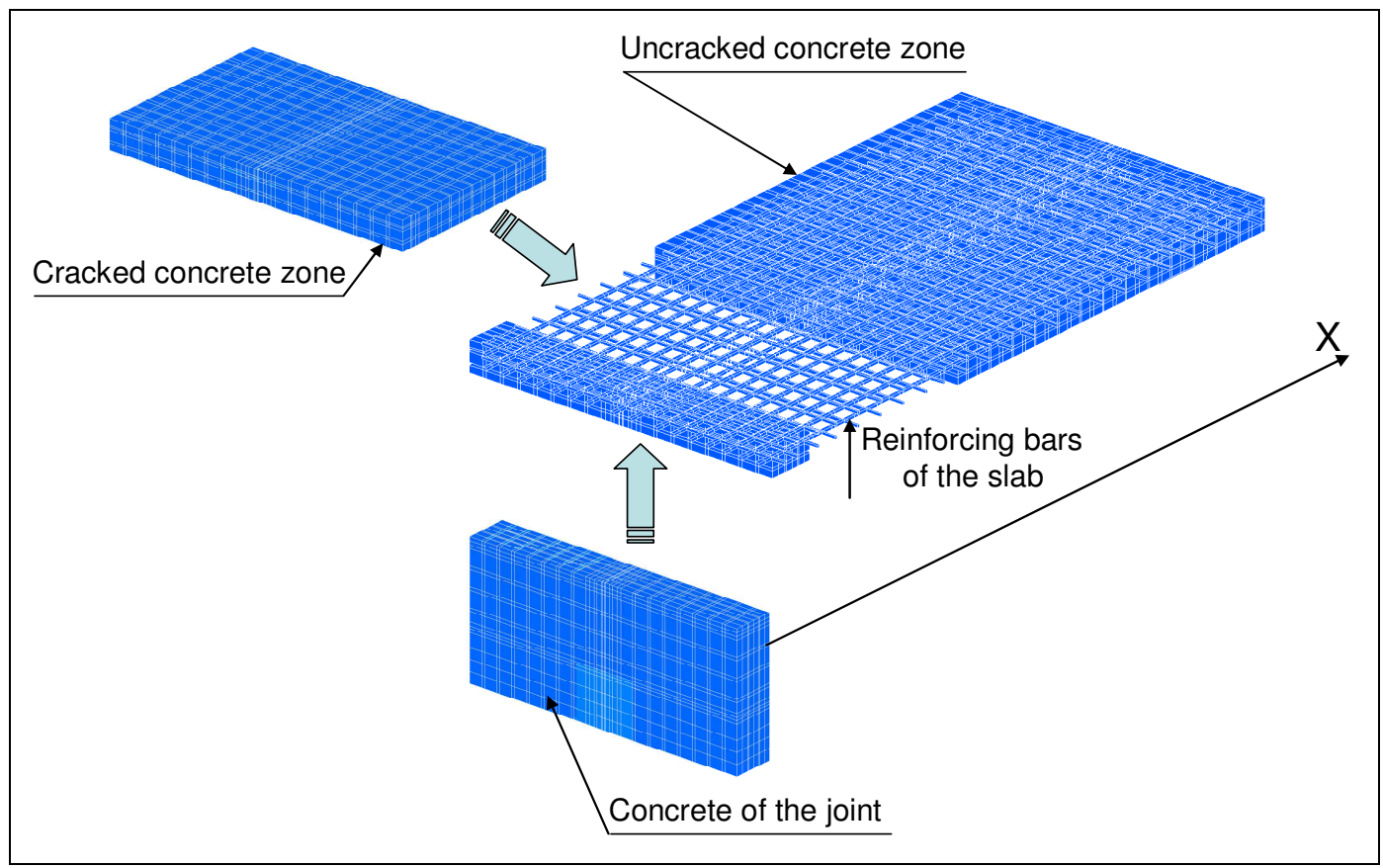

Fig. 8-3D model details - Concrete and reinforcing bars.

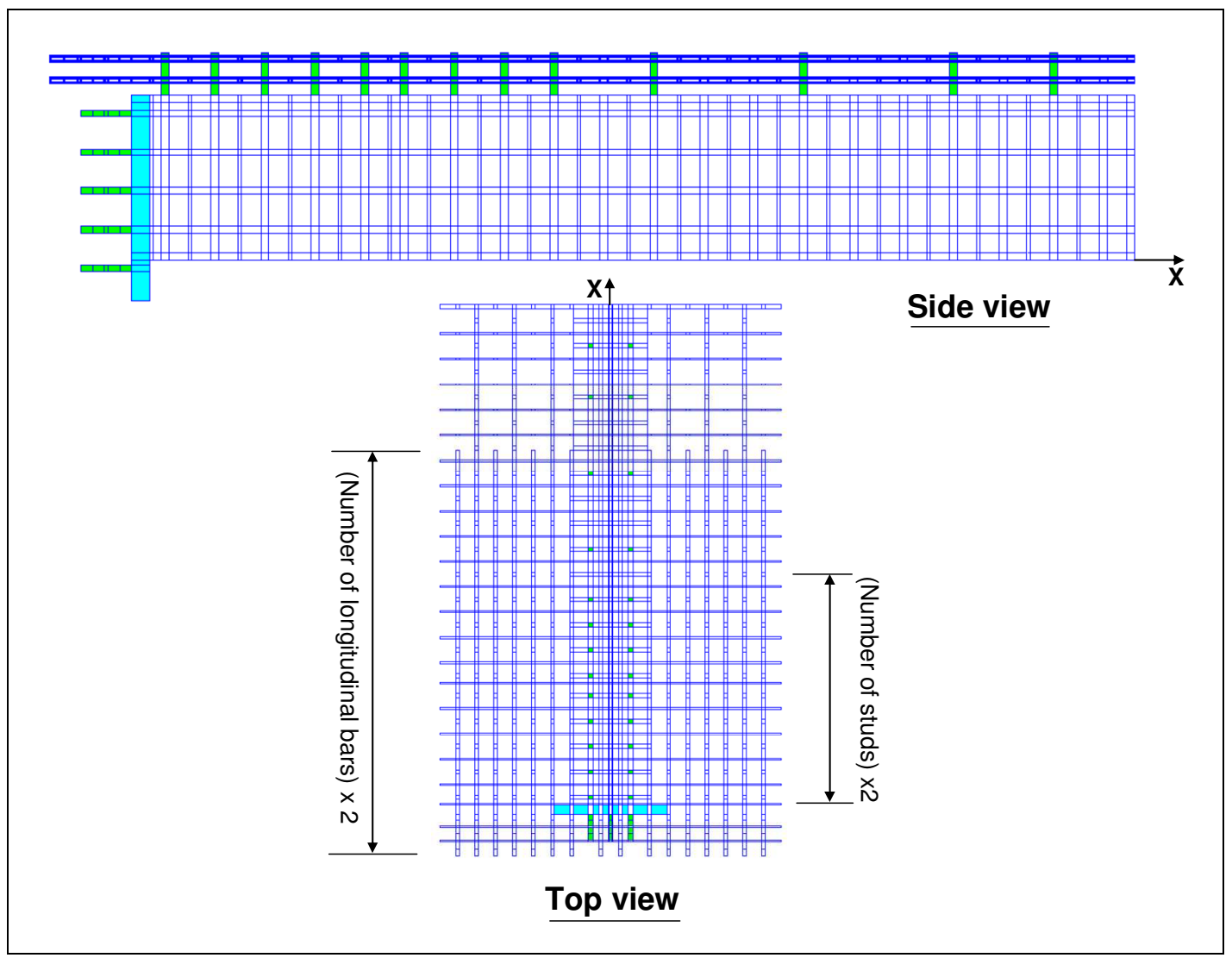

Fig. 9-3D model details - Top and side views. 


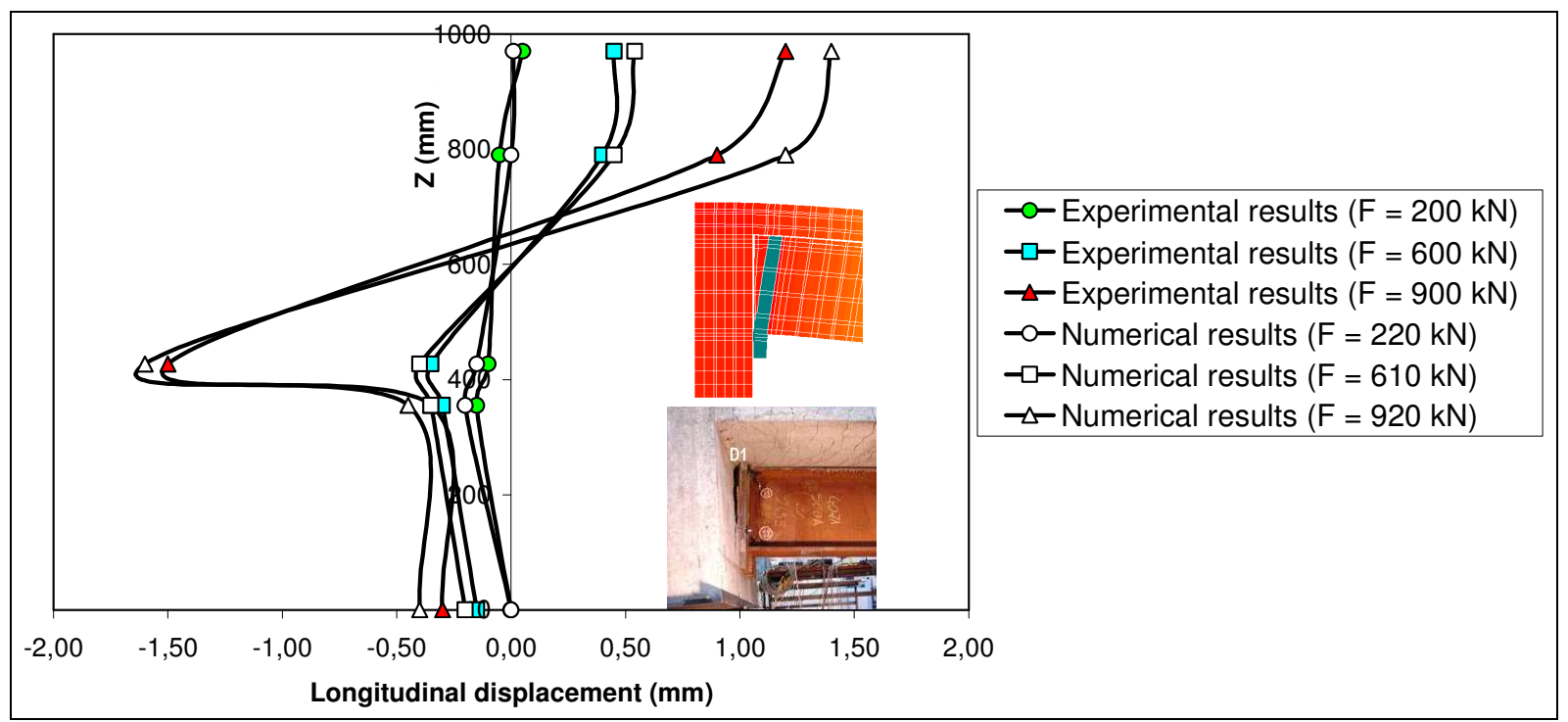

Fig. 10 - Longitudinal displacements $U_{x x}$ of the butt-plate.

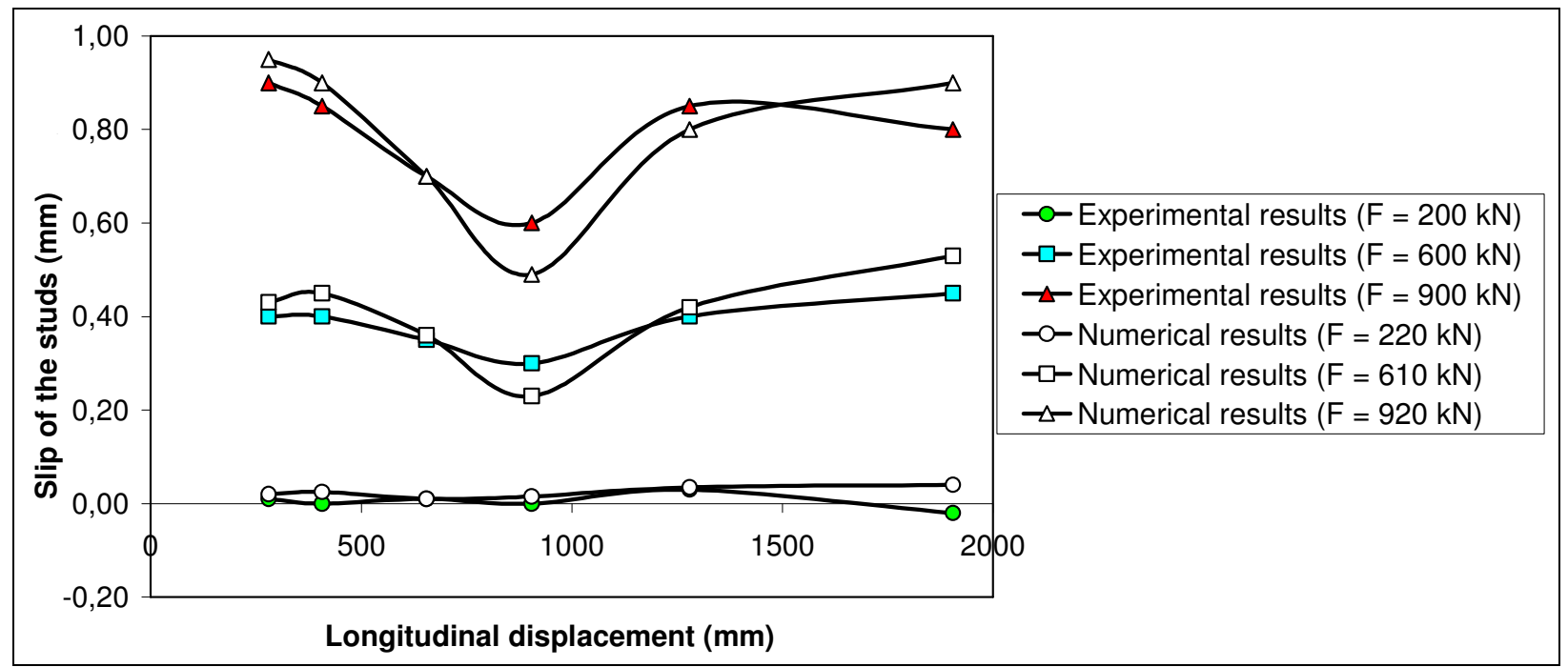

Fig. 11 - Slip of the vertical studs.

\section{Beam finite element model applied to joints $\mathrm{C} 1$ and $\mathrm{C} 2$ with concrete embedding}

The geometry of the joint is clearly three-dimensional. It could be expected that a thorough investigation of the stress distribution inside the embedded zone would need a 3D finite element model using solid elements. In fact, such model does not give all guarantees of reliable results due to the complex nonlinear interaction between the steel and the concrete, through the studs and direct contact. So, a first simple and effective investigation has been carried out in order to reproduce a global flexural behaviour. The part of a continuous composite beam located over its supports can be accurately modeled by plane beam finite elements, the slip at the interfaces being taken into account. The initial conception of the specimen tries to ensure the continuity of the beam. Consequently, it appeared rapidly that beam models were still applicable and could give valuable informations. 


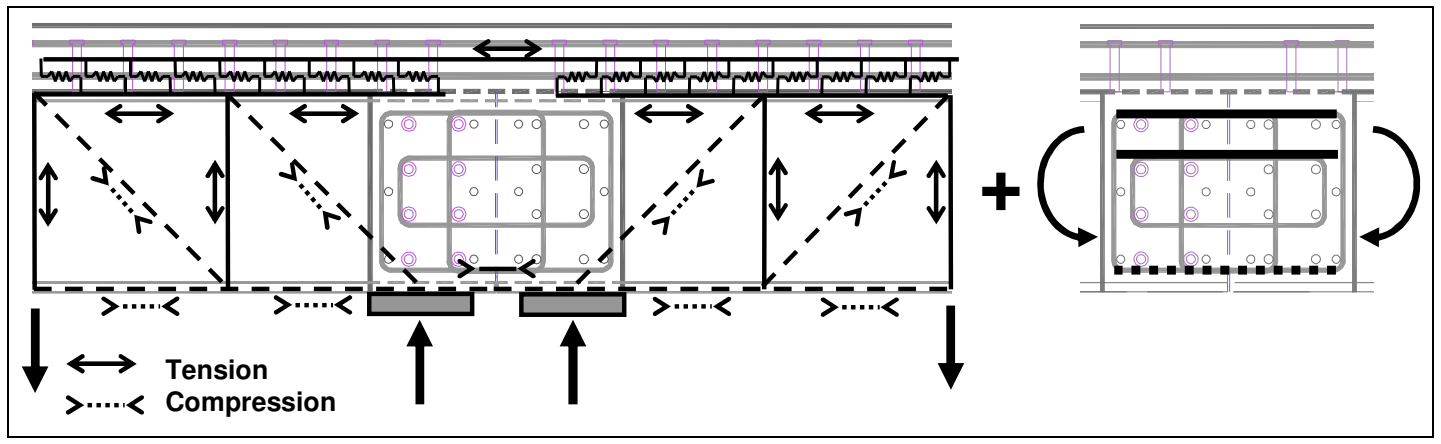

Fig. $13 \mathrm{a}$ and $\mathrm{b}-$ Global strut and tie model (a) and contribution of the embedding (b)

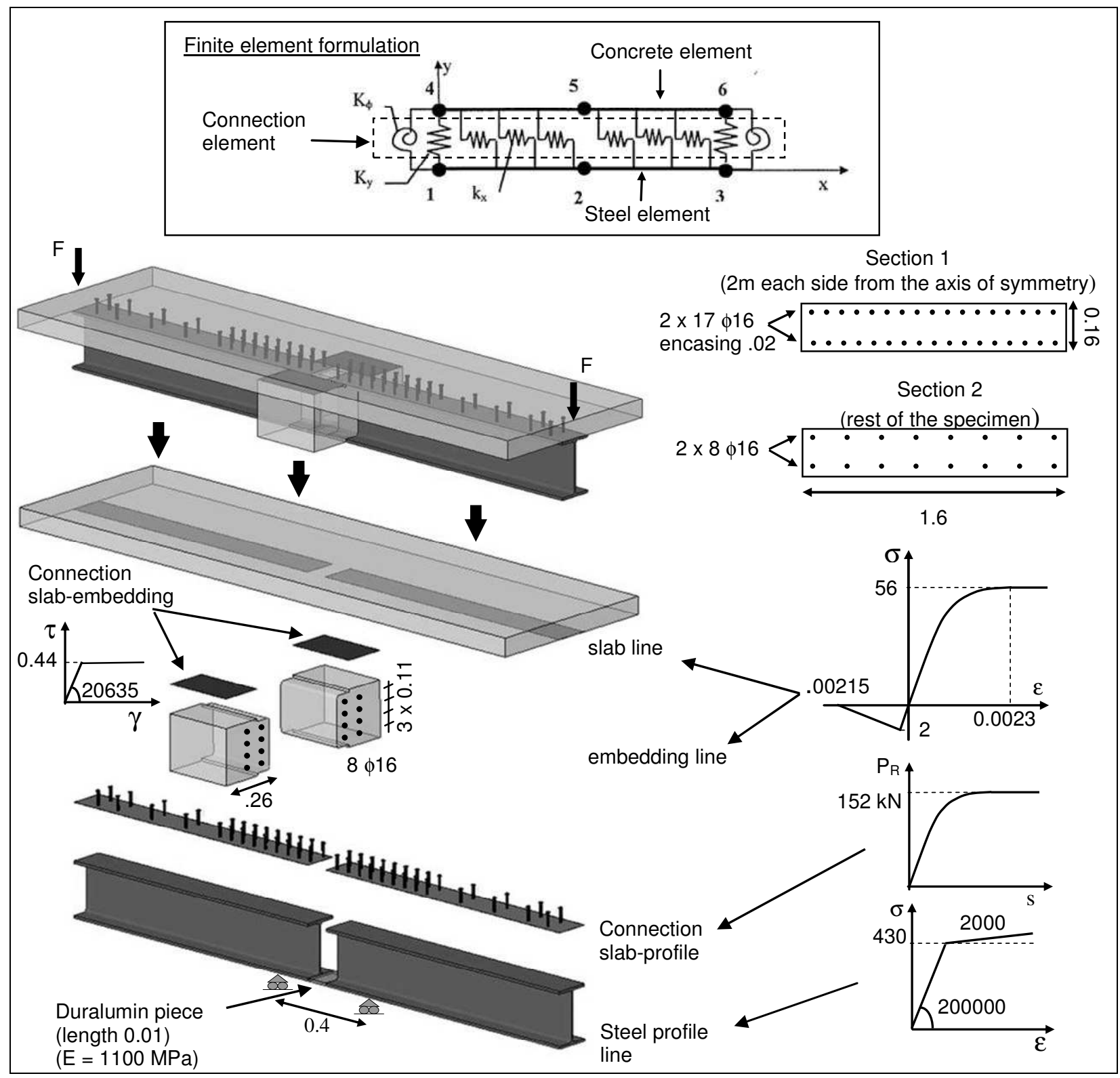

Fig. 14 - Presentation of the finite elements and of the numerical model (Units : MPa and m) 
Indeed, considering a strut and tie model (Figure 13.a) and thinking of differences with a classical joint with a continuous steel profile, the discontinuity has no effect on the lower compression strut thanks to the piece of contact. The discontinuity of the upper flange induces a total deviation of the upper tension tie in the slab, but with no real spatial local impact. Considering the web, no shear stress has to cross the joint from one side to the other due to the symmetry of the experimental loading. The bending role of the web is cancelled; but it is replaced by a transmission through the embedding (Figure 13.b) whom resistance has been set by design equal to $15 \%$ of the total bending capacity which is equivalent to the part of the global moment supported by the web outside the joint. This embedding flexure is evidently a 3D phenomenon, including a transversal diffusion of the stresses and a complex interaction with the slab and the steel profile. However the small part of the embedding in global flexure lowers the effects of the hypotheses that will have to be set to model it by a plane beam.

Consequently, a plane beam modeling has been undertaken using FINELG software [5], developed at the University of Liège and Greisch engineering office. Separated specific finite elements with 3 nodes are used for concrete and steel parts of the structure. They are bounded by a connection element (Fig. 14) with rigid transversal and rotational springs to avoid uplifting and with a uniform distribution of longitudinal springs whose rigidity $\mathrm{k}_{\mathrm{x}}$ is obtained from the force-slip relationship of the studs.

An exploded view of the topology of the model is presented in figure 4. Three parallel lines of beam elements are considered. The two main lines, for the steel and the concrete slab, are continuous over the length of the specimen. At the support, the part of concrete not included in the slab is represented by a new concrete line called "embedding". An effective width of $52 \mathrm{~cm}$ is considered for this part. In each section all lines are supposed to have the same rotation and vertical displacements, but a longitudinal slip is possible. Longitudinal restraints are only defined between the slab and the steel profile and between the slab and the embedding. Mechanical properties are synthesized in figure 14. Due to the initial cyclic loading, the duralumin piece is damaged and its experimental stiffness is measured equal to $1100 \mathrm{MPa}$. In figures 15 and 16 , experimental vertical displacements at the actuators location and slip along the slab-profile interface are compared against the results from numerical simulation. A relatively good agreement is obtained in both cases. This confirms the hypotheses set from the preliminary design. Further the ability of this simplified 2D model to simulate the behaviour of a such joint allows to consider the future development of an analytical component design approach.

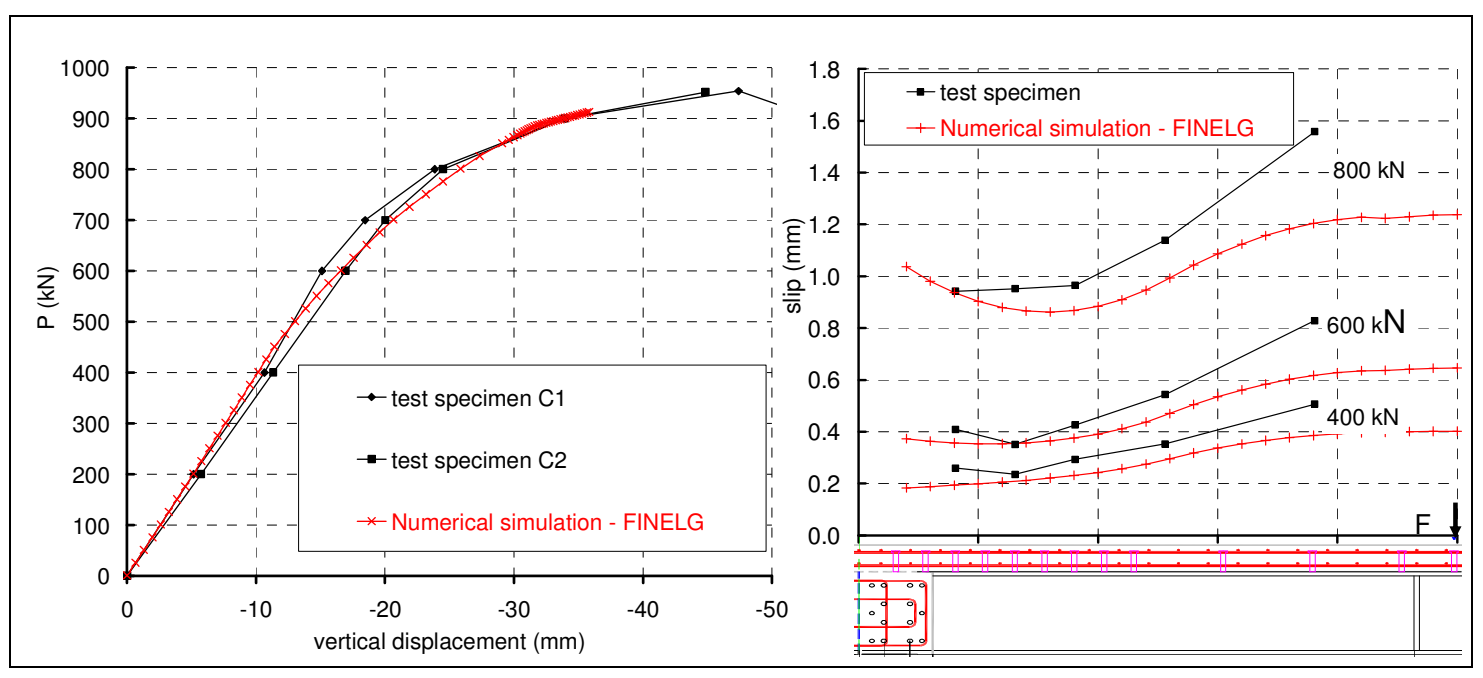

Fig. 15 -Vertical displacements at actuators.

Fig. 16 - Slip deck-profile distribution. 


\section{CONCLUSION}

The choice of a specific F.E. model for beam-to-beam composite joints mostly depends on its complexity and the phenomena we want to analyze. The most important rule is to respect the mechanical scheme of the joint behaviour. The proposed models for the joint solutions under investigation are based on simplifications affecting differently the results as well as the computation time. On the whole, the comparison between numerical and experimental results appears satisfactory and well-adapted to each type of joint. Even if some improvements could be added to the actual models, they should give at least necessary data for future design methods. With this aim in mind, several numerical simulations are planned to study the influence of some parameters on the design variables. For example :

- For the shell and 3D beam finite element model applied to joints A2 with cover-plates, the influence of a single contact material between the bottom flanges should be investigated as well as the influence of possible slip between the girder and the cover-plates.

- For the 3D solid finite element model applied to joint B with butt-plates, the thickness of the butt-plate and the rebars and studs density in the slab could be varied.

- For the beam finite element model applied to joints $\mathrm{C} 1$ and $\mathrm{C} 2$ with concrete embedding, the contact material is also of special interest.

\section{ACKNOWLEDGEMENTS}

The authors would like to thank IREX, the "French Ministry of Ecology and Sustainable Development", ArcelorMittal-Research and SNCF-Engineering for their financial and technical support through the national project MIKTI.

\section{References}

Ahmed B. Numerical modeling of semi-rigid composite joints. Ph.D. thesis. UK: University of Nottingham; 1996.

ARIBERT J.M., XU H. et RAGNEAU E., Theoretical investigation of moment redistribution on composite continuous beams of different classes. ASCE proceedings of COMPOSITE III Conference in Irsee, Germany - June 9-14, 1996 (p. 392-405).

CASTEM 2000, Un code de calcul aux elements finis, CEA/DMT/LAMS, Sarclay, France.

Chung W., Sotelino E.D. Three-dimensional finite element modeling of composite girder bridges. Engineering Structures 28 (2006) 63-71.

ECCS STEEL RTD PROGRAMME (CECA), Composite Bridge Design for Small and Medium Spans, RWTH-CTICM-PROFILARBED, Interim Report N², 2000.

Fu F., Lam D., Ye JQ. Parametric study of semi-rigid composite connections with 3D finite element approach. Engineering Structures 2006.07.003 (in press).

Lachal A., Aribert J.M., National Research Project MIKTI, Theme 1, Design of outstanding decks in the framework of small spans, Subject 1-B: Innovative techniques to connect continuous beams, specifications. Research report, feb 2002.

Lachal A., Hechler O., Kaing S.S. and Aribert J.M., Experimental investigations of the shear connection behaviour in joints of composite bridges. Composite VI, Devil's Thumb Ranch, Colorado, 20-25 July 2008.

Sieffert Y., Michel G., Ramondenc Ph., Jullien JF. Effects of the diaphragm at mid-span on static and dynamic behaviour of composite railway bridge: A case study. Engineering Structures 28 (2006) 1543-1554. 